\title{
Drooling in Parkinson's Disease: Prevalence and Progression from the Non-motor International Longitudinal Study
}

\author{
Daniel J. van Wamelen ${ }^{1,2,3} \cdot$ Valentina Leta $^{1,2}$. Julia Johnson ${ }^{2} \cdot$ Claudia Lazcano Ocampo $^{1,2,4}$. \\ Aleksandra M. Podlewska ${ }^{1,2} \cdot$ Katarina Rukavina ${ }^{1,2} \cdot$ Alexandra Rizos $^{1,2} \cdot$ Pablo Martinez-Martin $^{5}$. \\ K. Ray Chaudhuri ${ }^{1,2}$
}

Received: 1 November 2019 / Accepted: 22 February 2020 / Published online: 4 March 2020

(c) The Author(s) 2020

\begin{abstract}
Sialorrhoea in Parkinson's disease (PD) is an often neglected yet key non-motor symptom with impact on patient quality of life. However, previous studies have shown a broad range of prevalence figures. To assess prevalence of drooling in PD and its relationship to quality of life, we performed a retrospective analysis of 728 consecutive PD patients who had a baseline and follow-up assessment as part of the Non-motor International Longitudinal Study (NILS), and for whom drooling presence and severity were available, assessed through the Non-Motor Symptoms Scale (NMSS). In addition, we analysed the prevalence of associated dysphagia through self-reported outcomes. Quality of life was assessed through the PDQ-8 scale. Baseline (disease duration 5.6 years) prevalence of drooling was $37.2 \%$ (score $\geq 1$ NMSS question 19), and after $3.27 \pm 1.74$ years follow-up, this was $40.1 \%(p=0.17)$. The prevalence of drooling increased with age $(p<0.001)$. The severity of drooling, however, did not change $(p=0.12)$. While in 456 patients without drooling at baseline, only $16 \%(n=73)$ had dysphagia (question 20 of the NMSS), in those with drooling this was $34.3 \%(p<0.001)$. At follow-up, the number of patients with dysphagia had increased, $20.4 \%$ with no drooling had dysphagia, and $43.6 \%$ with drooling had dysphagia. Both at baseline and follow-up, drooling severity was significantly positively associated with quality of life (PDQ-8; $r=0.199 ; p<0.001$ ). In moderately advanced PD patients, subjective drooling occurs in over one-third of patients and was significantly associated with decreased quality of life. Dysphagia occurred significantly more often in patients with drooling.
\end{abstract}

Keywords Parkinson's disease $\cdot$ Drooling $\cdot$ Dysphagia $\cdot$ Non-motor symptoms scale $\cdot$ Deglutition $\cdot$ Deglutition disorders

Daniel J. van Wamelen and Valentina Leta have contributed equally and are to be considered as joint first authors.

Daniel J. van Wamelen

Daniel.van_wamelen@kcl.ac.uk

1 Institute of Psychiatry, Psychology \& Neuroscience, Department of Basic and Clinical Neurosciences, King's College London, De Crespigny Park, London SE5 8AF, UK

2 Parkinson Foundation Centre of Excellence At King's College Hospital, Denmark Hill, London SE5 9RS, UK

3 Donders Institute for Brain, Cognition and Behaviour, Department of Neurology, Radboud University Medical Centre, Nijmegen, the Netherlands

4 Department of Neurology, Hospital Sotero del Rio, Santiago, Chile

5 Center for Networked Biomedical Research in Neurodegenerative Diseases (CIBERNED), Carlos III Institute of Health, 28031 Madrid, Spain

\section{Introduction}

Drooling, or sialorrhoea, is a frequent non-motor symptom in Parkinson's disease (PD). A wide prevalence range has been reported in the literature, ranging from 10 to $84 \%$ [1-5], and drooling has a negative impact on both patients and caregivers and is rated by patients as one of the top 10 most bothersome symptoms $[6,7]$. The broad range is likely due to the lack of a standard definition and diagnostic criteria, and differences in the studied PD populations [5]. Drooling in PD appears to be primarily related to reduced swallowing efficiency, and not to an increase in saliva production [8]. Further contributing factors are reduced lip seal as part of hypomimia, sensory and postural changes and poor awareness of drooling [9]. Moreover, sialorrhoea is more prevalent in patients with cognitive impairment $[10,11]$.

Although many contributing factors to sialorhoea have been identified in PD, the exact cause of sialorrhea has not 
been fully clarified. The strongest evidence is that for a relationship between dysphagia and drooling $[1,12]$. Other studies have shown that, based on measures of salivation [13-15], and scintigraphic analysis [16], impaired swallowing is the most likely cause of drooling in PD. The importance of drooling in PD has been demonstrated not only by the associated risk of dry mouth, impact on bolus formation, loss of antibacterial effects of saliva, perioral dermatological changes, dehydration, and increased speech difficulties $[8,17,18]$, together with its social impact and associated social isolation. As the current literature in drooling in PD is often conflicting, we aimed to expand the current knowledge by assessing sialorrhoea and associated symptoms in a large cohort of longitudinally followed PD patients. The aim of the current study was to examine the prevalence of drooling, and its progression, across different age groups in patients with PD, and assess the impact on quality of life. Our hypothesis was that the prevalence of sialorrhoea in PD would increase with age and would negatively impact on quality of life.

\section{Methods}

This study was a retrospective project using data from the prospective, longitudinal, Non-motor International Longitudinal Study (NILS). The NILS Study enables the charting of the natural history of non-motor symptoms together with treatment response and clinico-pathological correlations in PD patients. The study is adopted as a national study by the National Institute of Health Research in the UK (UKCRN No: 10,084) and involves 30 centres around the world, currently containing data for over 1600 PD patients who had a baseline assessment, and for some of whom a follow-up of up to seven years is available. The study has been authorised by local ethics committees (NRES SouthEast London REC3, 10,084, 10/H0808/141). All patients gave written consent prior to study procedures in accordance with the Declaration of Helsinki. The main inclusion criterion was a diagnosis of idiopathic PD according to the UK Brain Bank criteria. Exclusion criteria were (1) diagnosis of Parkinsonism different to idiopathic PD; (2) dementia (MMSE scores of 26 or less [19]); (3) inability to give informed consent to participate in the study.

For the current analysis, we used data from patients clinically diagnosed with idiopathic PD and whose data were entered between November 2011 and July 2019 and who were included in one of the UK centres for NILS. Data for analysis were extracted on July 1st 2019. Only patients who had at least one follow-up assessment as part of the NILS study were included in the analysis, and data for the last available follow-up assessment were used for analysis. Data extracted from the NILS database concerned sex, age, disease onset and duration (in years), and Levodopa equivalent daily dose (LEDD). Patient-reported outcomes included Hospital Anxiety and Depression Scale (HADS) [20], a quality of life measure (PDQ-8) [21], Parkinson's Disease Sleep Scale-version 1 (PDSS) [22], Mini Mental State Examination (MMSE) [23], and Epworth Sleepiness Scale (ESS) [24] scores. Clinician-based evaluations included Hoehn and Yahr (HY) staging [25], Scales for Outcomes in PD [26], and Non-Motor Symptoms Scale (NMSS) and Questionnaire (NMSQ) scores [27, 28]. The NMSS categorises the frequency and severity of the nonmotor symptoms of PD by nine domains: cardiovascular, sleep/fatigue, mood/apathy, perceptual problems/hallucinations, attention/memory, gastrointestinal tract, urinary function, sexual function, and miscellaneous [28].

The presence and frequency of drooling in the studied cohort was based on the scores for question 19 of the NMSS, asking about the presence and frequency of drooling. Using NMSS question 19 scores we stratified participants based on severity of drooling: (1) absent to mild (scores 0-3), (2) moderate (scores 4-7), and severe (scores 8-12). In addition, drooling was scored as either absent (score 0 on question 19 of the NMSS) or present (scores 1-12). Subsequently we assessed prevalence, and progression of drooling and drooling severity in our cohort. Secondary outcomes included a linear regression analysis to assess baseline predictors for drooling severity at follow-up. To this end, the raw scores for NMSS question 19 scores were used as a dependent continuous variable, and baseline demographics, and specific non-motor (HADS, PDSS, MMSE, ESS) and motor characteristics (SCOPA) as independent continuous variables. As the data were not normally distributed (Shapiro-Francia test), group differences at baseline and follow-up were tested with Mann-Whitney $U$ test or Kruskal-Wallis test, where appropriate. To test for gender differences, Pearson Chisquare analysis was used. To test for binominal differences in baseline and follow-up drooling and dysphagia prevalence we used the McNemar test, and to test baseline to follow-up difference for continuous variables we used the Wilcoxon signed-rank test. For correlations Spearman's $\rho$ was used. All data were analysed using SPSS Version 25 (IBM SPSS Statistics for Windows, Version 25.0. Armonk, NY: IBM Corp.). Data are represented as mean \pm standard deviation, unless otherwise specified; a $p$ value of $<0.05$ was considered significant.

\section{Results}

Of the 1120 participants who had a baseline assessment as part of the NILS study, 796 had at least one follow-up assessment. Of these participants, 728 had NMSS scores 
Table 1 Demographic data for the 728 participants for whom drooling scores were available at the baseline and last follow-up assessments

\begin{tabular}{llll}
\hline & Baseline & Follow-up & $p$ value \\
\hline Gender (M/F) & $462 / 265(63.5 \% / 36.4 \%)$ & $462 / 265(63.5 \% / 36.4 \%)$ & N/A \\
Age $(\mathrm{yrs})$ & $65.72 \pm 10.87$ & $68.98 \pm 10.77$ & $<0.001$ \\
Disease duration (yrs) & $5.63 \pm 5.08$ & $8.90 \pm 5.37$ & $<0.001$ \\
Hoehn and Yahr stage & $2.19 \pm 0.89$ & $2.58 \pm 0.90$ & $<0.001$ \\
LEDD (mg) & $525.19 \pm 462.01$ & $712.21 \pm 468.78$ & $<0.001$ \\
SCOPA scores & & & $<0.001$ \\
Motor score & $9.85 \pm 5.11$ & $11.19 \pm 5.49$ & $<0.001$ \\
Activities of daily living & $5.29 \pm 3.40$ & $7.02 \pm 4.00$ & $<0.001$ \\
Motor complications & $1.68 \pm 2.53$ & $2.39 \pm 2.41$ & 0.012 \\
NMSS total scores & $45.48 \pm 36.47$ & $48.93 \pm 39.38$ & \\
\hline
\end{tabular}

Duration of follow-up was $3.27 \pm 1.74$ years (range $0.5-7.2$ years)

$F$ female, $L E D D$ levodopa equivalent daily dose, $M$ male, $N M S S$ non-motor symptoms scale, yrs years
Table 2 Prevalence of drooling (based on Non-Motor Symptoms Scale question 19) at baseline at follow-up

\begin{tabular}{llll}
\hline Drooling & Baseline & Follow-up & $p$ value \\
\hline Entire cohort $(n=728)$ & $271(37.2 \%)$ & $292(40.1 \%)$ & $0.17^{\mathrm{a}}$ \\
Age $<50$ years $(n=66)$ & $16(24.2 \%)$ & $19(28.8 \%)$ & $0.55^{\mathrm{a}}$ \\
Age 50-65 years $(n=242)$ & $74(30.6 \%)$ & $80(33.1 \%)$ & $0.51^{\mathrm{a}}$ \\
Age 65-80 years $(n=361)$ & $154(42.7 \%)$ & $163(45.2 \%)$ & $0.47^{\mathrm{a}}$ \\
Age $>$ 80 years $(n=59)$ & $27(45.8 \%)$ & $30(55.8 \%)$ & $0.66^{\mathrm{a}}$ \\
$p$ value (across age groups) & $<0.001^{\mathrm{b}}$ & $0.002^{\mathrm{b}}$ & \\
\hline
\end{tabular}

Duration of follow-up was $3.27 \pm 1.74$ years (range $0.5-7.2$ years)

${ }^{\mathrm{a}} \mathrm{McNemar}$ test

${ }^{\mathrm{b}}$ Chi-square test

for question 19 (drooling) available for both baseline and follow-up analysis. Mean duration of follow-up for this cohort of 728 PD patients was $3.27 \pm 1.74$ years (range $0.5-7.2$ years). Other baseline demographic data are presented in Table 1.

At baseline prevalence of drooling was $37.2 \%$ (score of $\geq 1$ on NMSS question 19), and after the $3.27 \pm$ 1.74 years follow-up this the prevalence had remained stable at $40.1 \%$ (McNemar test; $p=0.17$; Table 2). Similar results were observed across the respective age groups, with the lowest prevalence $(24.2 \%)$ in the youngest $(<50$ years of age) patients, and the highest $(45.8 \%)$ in the older patients ( $>80$ years of age) (Fig. 1; Table 2). The prevalence of drooling increased with age, in all four age groups at baseline and follow-up (Wilcoxon test; $p<0.001$ and $p=0.002$, respectively; Fig. 1; Table 2), and drooling severity (as measured by NMSS question 19) showed a significant, yet almost negligible, association with age, both at baseline (Spearman's test; $\rho=0.134 ; p<0.001$ ) and at follow-up (Spearman's test; $\rho=0.159 ; p<0.001$ ). The severity of drooling did not change over the follow-up period, with mean scores of $1.53 \pm 2.71$ at baseline, and

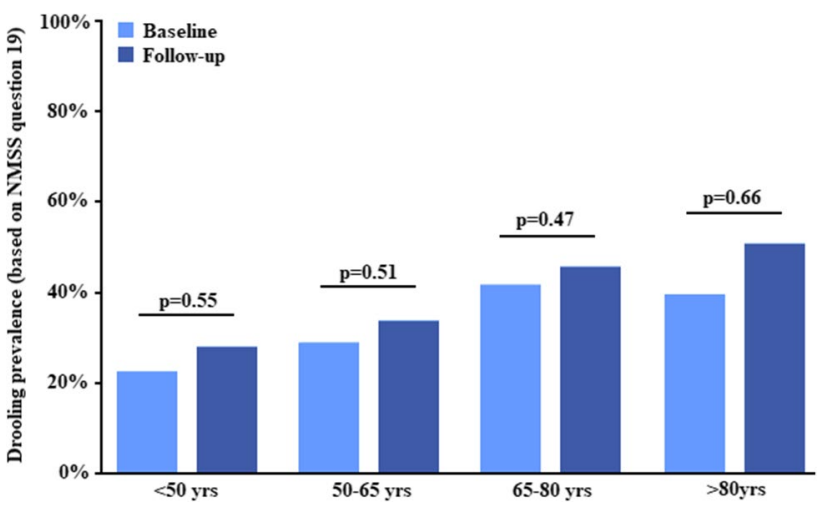

Fig. 1 Prevalence of drooling, as defined by question 19 of the NonMotor Symptoms Scale, at baseline and follow-up across four different age groups. NMSS non-motor symptom scale, yrs years. Duration of follow-up was $3.27 \pm 1.74$ years (range $0.5-7.2$ years)

$1.77 \pm 3.02$ at follow-up (Wilcoxon test; $p=0.12$ ). Subgroup analysis revealed that the latter was similar across all four age groups (Wilcoxon test; $p \geq 0.11$; Fig. 2).

When looking at the influence of disease stage, we observed that drooling severity at both baseline and follow-up assessments increased with HY stage $(p<0.001$ (Wilcoxon signed-rank test), as well as drooling prevalence (McNemar test; $p<0.001$; Fig. 3). A similar pattern was observed with disease duration, where drooling was most prevalent in in the group of patients with 10.0-15.0 (51.8\% and $38.6 \%$ at baseline and follow-up, respectively) and $>15.0$ years disease duration $(48.9 \%$ and $48.9 \%$ at baseline and follow-up, respectively) (McNemar test; $p<0.0 .001$; Fig. 4).

Of the 456 patients without drooling at baseline, 73 (16.0\%) has dysphagia (determined by question 20 of the NMSS), whereas 93 out of 271 (34.3\%) PD patients with drooling had dysphagia (Chi-square test; $p<0.001$ ). 


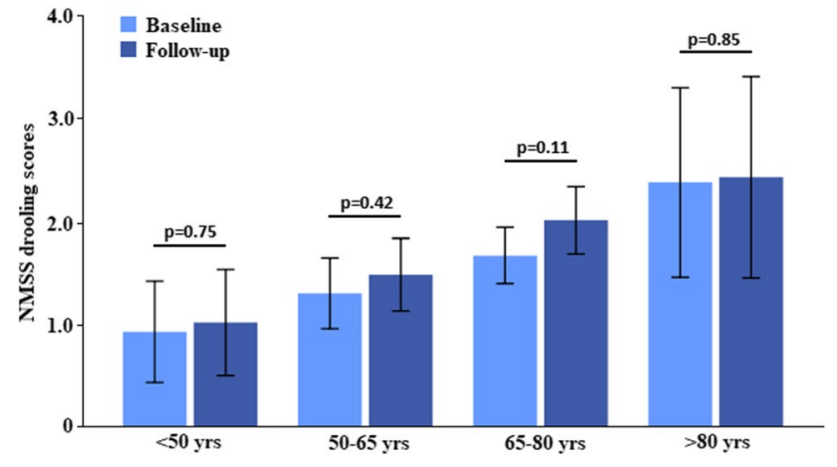

Fig. 2 Drooling severity, as defined by question 19 of the Non-Motor Symptoms Scale, at baseline and follow-up across four different age groups. NMSS non-motor symptom scale, yrs years. Bars represent 95\% confidence intervals
At follow-up, the number of patients with dysphagia had increased, and $20.4 \%$ (89 out of 436 patients) with no drooling had dysphagia, and 43.6\% (127 out of 291 patients) with drooling had dysphagia.

Both at baseline and at follow-up, drooling severity was significantly, yet almost negligibly, positively associated with PDQ-8 scores (higher scores indicating lower quality of life) (Spearman's test; $\rho=0.193, p<0.001$, and $\rho=$ $0.199, p<0.001$, respectively). A regression analysis $\left(R^{2}\right.$ $=0.122 ; p<0.001$ ) showed that drooling severity (defined by NMSS question 19) at follow-up was predicted by age ( $b$ $=0.198, p<0.001)$, MMSE scores $(b=0.127, p=0.013)$, and ESS scores $(b=0.142, p=0.012)$, but not by disease duration, LEDD, HADS subscores, PDSS scores, SCOPA subscores, or NMSS total scores at baseline $(p \geq 0.08)$. The interpretation of this regression model, however, was limited by the very low $R^{2}$.
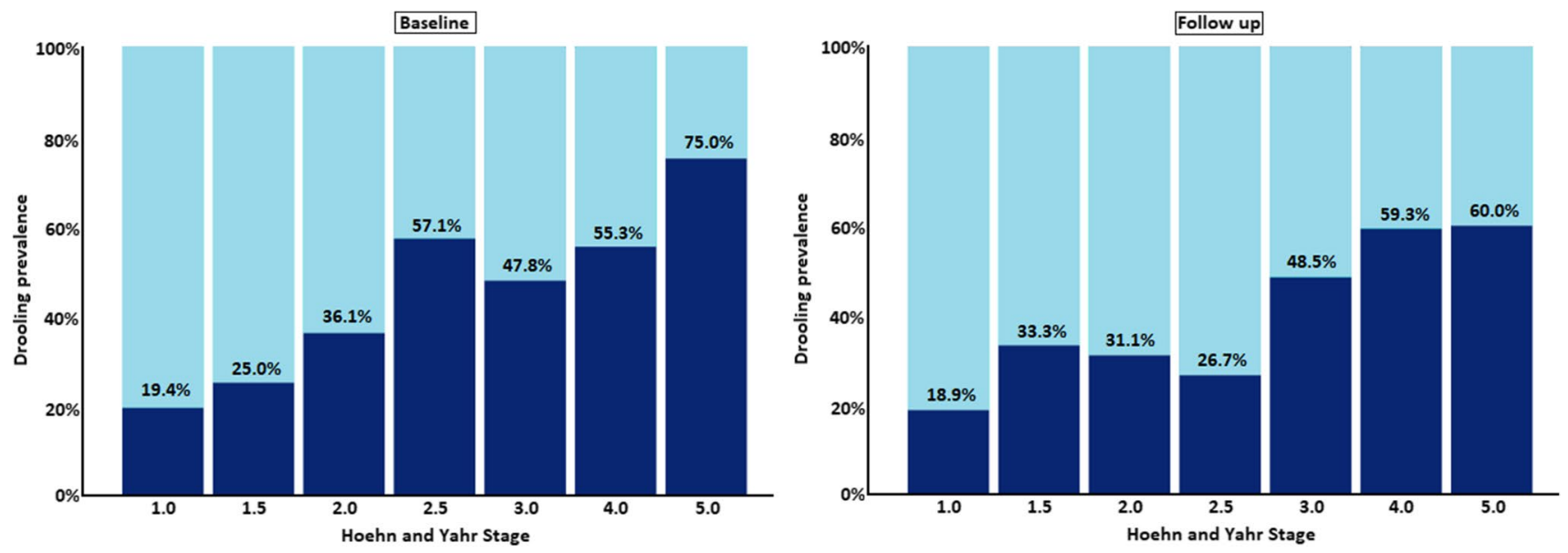

Fig. 3 Prevalence of drooling, as defined by question 19 of the Non-Motor Symptoms Scale, at baseline and follow-up across Hoehn and Yahr stages
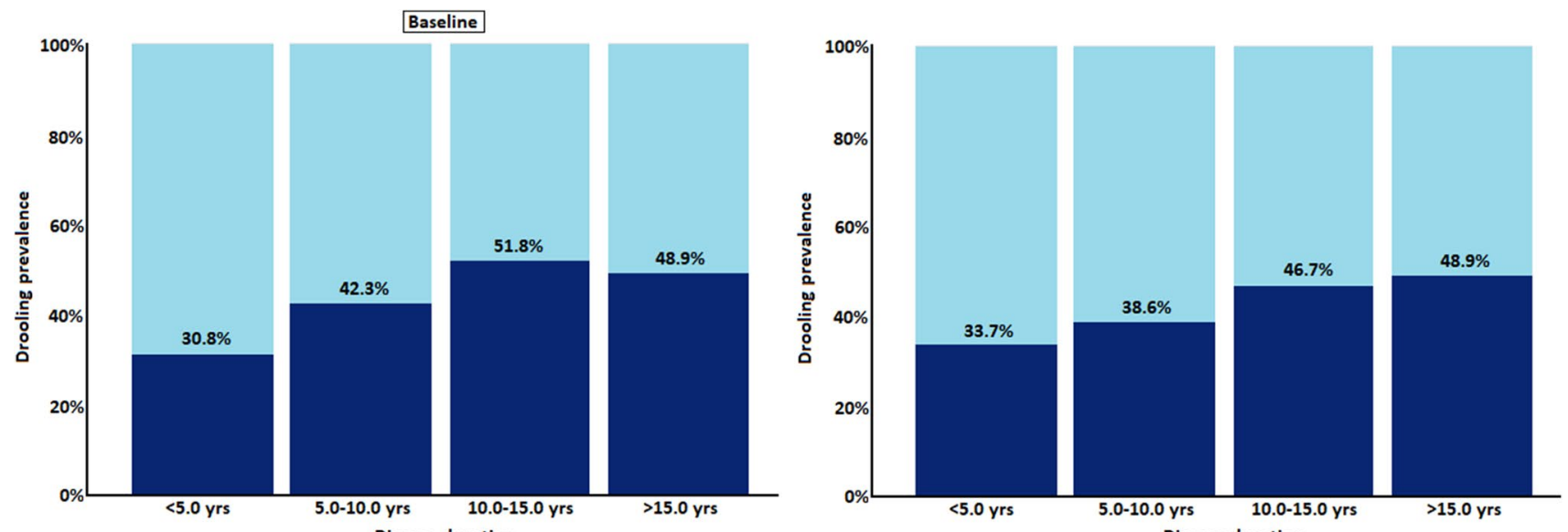

Fig. 4 Prevalence of drooling, as defined by question 19 of the Non-Motor Symptoms Scale, at baseline and follow-up across disease duration 


\section{Discussion}

This study represents one of the largest cohorts of PD patients in whom prevalence of drooling was reported, using a validated global NMS scale. Some of the key findings from this large real-life cohort-based data analysis in relation to subjective drooling in PD suggest that drooling occurred in $37.2 \%$ in our cohort of PD irrespective of HY stage, disease duration and gender, and that the prevalence of drooling was stable after a follow-up of over 3 years. The latter seems to suggest that treatment was either not initiated or proved ineffective. In addition, drooling appeared to have be associated with patient age, with the highest rates reported in those over 80 years of age. However, drooling severity, as assessed through the NMSS, did not increase over time. Dysphagia may be associated with the presence of drooling, and may need to be specifically considered when determining treatment approaches.

The prevalence of drooling observed in our cohort is similar to that observed in previous studies. Using the Non-Motor Symptom Questionnaire (NMSQ), Erro et al. observed a sialorrhoea frequency of $19.4 \%$ in 61 de-novo and untreated patients with PD, increasing to $33.8 \%$ after a follow-up of four years [29]. In another study deploying the NMSQ, Picillo and colleagues identified that sialorrhoea in 134 de-novo PD patients increased from 23.3\% to $25.0 \%$ in men after two years, while it decreased from 10.4 to $4.1 \%$ in women [30]. In the most comprehensive study looking at sialorrhoea (defined by the Unified PD Rating Scale drooling item), where 314 PD patients were followed for over 4 years, drooling was present in $11.7 \%$ of moderately advanced PD patients, increasing to $55.3 \%$ at follow-up $[31,32]$. Also, a recent prevalence study on drooling in PD performed in China showed that it is a common problem with the rate of $52.7 \%$ ( 273 out of 518 examined patients). The most common correlations were late onset of disease, higher levodopa equivalent daily doses, higher incidences of dysarthria, dysphagia and fluctuations, higher motor scores, and increased non-motor burden (NMSS) and depression, all affecting quality of life [33]. These studies show, similar to our cohort, that drooling occurs in all stages of PD, and is not an exclusive feature of advanced PD. The differences in prevalence rates may be explained by the use of different (validated) tools to assess siallorhoea and the fact that a large part of patients tend to underreport non-motor symptoms [34].

In our cohort we observed that drooling was often associated with dysphagia, even though it was measured through patient-reported outcomes, and at the last follow-up visits almost half of the patients with drooling had dysphagia. This number is comparable to what was observed in several recent studies. Nienstedt et al. found that in 110 PD patients with a mean disease duration of 9.7 years, half had drooling, and this was associated with dysphagia. In addition, they observed that $59 \%$ of patients with severe drooling had dysphagia [35]. Drooling was, as in other studies, also associated with cognitive performance. As drooling appears to occur more often in individuals with PD during cognitively demanding tasks, such as a language task [36], cognitive decline may further contribute to the presence of sialorrhoea. This seems to be supported by observations in other studies showing that drooling in PD is associated with cognitive decline, similar to our findings. Rana and colleagues showed that the presence of dementia, as assessed through the DSM-IV criteria, was significantly associated with the presence of drooling [11]. The link between cognitive performance and drooling in PD, however, could not be confirmed in all studies [33].

To our knowledge, the current study reports the, to date, largest cohort of PD patients in whom sialorrhoea was reported. Despite this, some limitations of our study have to be acknowledged. Firstly, drooling was not assessed through specialist clinical examination, but its presence was assessed in a retrospective cohort. Even though such information may be influenced by e.g. recall bias, the data obtained reflect a real-world experience where similar information is obtained in clinic, where formal assessments are often limited due to time pressure. In addition, a review by the Movement Disorders Task Force on Rating Scales for Parkinson's Disease suggest the use of NMSQ (recommended) and NMSS (suggested) for global dysautonomia of which drooling and dysphagia form part and NMSS was used in this study [37]. The reason for the NMSS having only a 'suggested' recommendation was because of the lack of validation studies other than the original publication, but in the meantime several studies have further validated the NMSS [38-40]. In addition, we did not have specific information on the treatment for drooling, yet the same prevalence of drooling at baseline and follow-up suggests either that drooling was not declared or detected in clinic or ineffectively managed. The latter issue is particularly relevant in light of the recent licencing of Xeomin (Incobotulinumtoxin A) for the management of sialorrhea in PD.

In summary, we observed that subjective sialorrhoea was present in over one-third of participants in a cohort of moderately advanced PD patients, with a stable frequency over a follow-up of over 3 years. These findings confirm those made in previous studies, whereas a novel finding in our study was the effect of age on drooling prevalence in PD. This study underlines the importance of drooling in $\mathrm{PD}$, as well as an urgent need for further studies focusing on appropriate interventions to reduce the prevalence of this bothersome symptom in PD. This is especially relevant as drooling can be socially isolating and embarrassing for PD patients. 
Acknowledgements We acknowledge data collection efforts by all contributors, collaborators, and administrative staff of the NILS study. The views expressed are those of the author(s) and not necessarily those of the NHS, the NIHR or the Department of Health.

Author Contributions All authors contributed to the study conception and design. Material preparation, data collection and analysis were performed by DVW, VL, and KRC. The first draft of the manuscript was written by DVW and VL and all authors commented on previous versions of the manuscript. All authors read and approved the final manuscript.

Funding This research did not receive specific funding.

\section{Compliance with Ethical Standards}

Conflict of interest The authors declare that there are no conflicts of interest relevant to this work. Financial disclosures not related to this work: Dr. van Wamelen reports grants and personal fees from Britannia Pharmaceuticals, personal fees from Invisio Pharmaceuticals, outside the submitted work. Dr. Leta reports personal fees from Britannia Pharmaceuticals, personal fees from Invisio Pharmaceuticals, grants from Parkinson's UK, grants from Bial, outside the submitted work. Mrs. Johnson has nothing to disclose. Dr. Lazcano-Ocampo has nothing to disclose. Ms. Podlewska reports personal fees from Britannia Pharmaceuticals, grants from Welcome Trust, outside the submitted work. Dr. Rukavina has nothing to disclose. Mrs. Rizos has nothing to disclose. Prof. Martinez-Martin reports personal fees from Editorial Viguera, grants and personal fees from International Parkinson and Movement Disorder Society, personal fees from HM Hospitales de Madrid, other from King's Parkinson's Disease Pain scale, outside the submitted work. Prof. Ray Chaudhuri reports personal fees from Abbvie, personal fees from Britannia Pharmaceuticals, personal fees from UCB, personal fees from Mundipharma, personal fees from Zambon, personal fees from Global Kinetics, personal fees from Bial, grants from Parkinson's UK, grants from NIHR, grants from PDNMG, grants from Kirby Laing, grants from NPF, other from AbbVie, other from UCB, other from Sunovion, other from Pfizer, other from Jazz Pharma, from Bial, from Global Kinetics, grants from Welcome Trust, outside the submitted work.

Open Access This article is licensed under a Creative Commons Attribution 4.0 International License, which permits use, sharing, adaptation, distribution and reproduction in any medium or format, as long as you give appropriate credit to the original author(s) and the source, provide a link to the Creative Commons licence, and indicate if changes were made. The images or other third party material in this article are included in the article's Creative Commons licence, unless indicated otherwise in a credit line to the material. If material is not included in the article's Creative Commons licence and your intended use is not permitted by statutory regulation or exceeds the permitted use, you will need to obtain permission directly from the copyright holder. To view a copy of this licence, visit http://creativecommons.org/licenses/by/4.0/.

\section{References}

1. Ou R, Guo X, Wei Q, Cao B, Yang J, Song W, Shao N, Zhao B, Chen X, Shang H. Prevalence and clinical correlates of drooling in Parkinson disease: a study on 518 Chinese patients. Parkinsonism Relat Disord. 2015;21(3):211-5. https://doi.org/10.1016/j.parkr eldis.2014.12.004.
2. van der Marck MA, Kalf JG, Sturkenboom IH, Nijkrake MJ, Munneke M, Bloem BR. Multidisciplinary care for patients with Parkinson's disease. Parkinsonism Relat Disord. 2009;15(Suppl 3):S219-223. https://doi.org/10.1016/s1353-8020(09)70819-3.

3. Nicaretta DH, Rosso AL, Mattos JP, Maliska C, Costa MM. Dysphagia and sialorrhea: the relationship to Parkinson's disease. Arquivos de Gastroenterol. 2013;50(1):42-9.

4. Scott B, Borgman A, Engler H, Johnels B, Aquilonius SM. Gender differences in Parkinson's disease symptom profile. Acta Neurol Scand. 2000;102(1):37-433.

5. Srivanitchapoom P, Pandey S, Hallett M. Drooling in Parkinson's disease: a review. Parkinsonism Relat Disord. 2014;20(11):1109_ 18. https://doi.org/10.1016/j.parkreldis.2014.08.013.

6. Kalf JG, Smit AM, Bloem BR, Zwarts MJ, Munneke M. Impact of drooling in Parkinson's disease. J Neurol. 2007;254(9):1227-322. https://doi.org/10.1007/s00415-007-0508-9.

7. Politis M, Wu K, Molloy S, Bain GP, Chaudhuri KR, Piccini P. Parkinson's disease symptoms: the patient's perspective. Mov Disord. 2010;25(11):1646-51. https://doi.org/10.1002/mds.23135.

8. Zlotnik Y, Balash Y, Korczyn AD, Giladi N, Gurevich T. Disorders of the oral cavity in Parkinson's disease and parkinsonian syndromes. Parkinson's Dis. 2015;2015:379482. https://doi. org/10.1155/2015/379482.

9. Meningaud J-P, Pitak-Arnnop P, Chikhani L, Bertrand J-C. Drooling of saliva: a review of the etiology and management options. Oral Surg Oral Med Oral Pathol Oral Radiol Endodontol. 2006;101(1):48-57.

10. Kalf JG, Munneke M, van den Engel-Hoek L, de Swart BJ, Borm GF, Bloem BR, Zwarts MJ. Pathophysiology of diurnal drooling in Parkinson's disease. Mov Disord. 2011;26(9):1670-6. https:// doi.org/10.1002/mds.23720.

11. Rana AQ, Khondker S, Kabir A, Owalia A, Khondker S, Emre M. Impact of cognitive dysfunction on drooling in Parkinson's disease. Eur Neurol. 2013;70(1-2):42-5. https://doi. org/10.1159/000348571.

12. Perez-Lloret S, Negre-Pages L, Ojero-Senard A, Damier P, Destee A, Tison F, Merello M, Rascol O. Oro-buccal symptoms (dysphagia, dysarthria, and sialorrhea) in patients with Parkinson's disease: preliminary analysis from the French COPARK cohort. Eur J Neurol. 2012;19(1):28-37. https://doi.org/10.111 1/j.1468-1331.2011.03402.x.

13. Bagheri H, Damase-Michel C, Lapeyre-Mestre M, Cismondo S, O'Connell D, Senard JM, Rascol O, Montastruc JL. A study of salivary secretion in Parkinson's disease. Clin Neuropharmacol. 1999;22(4):213-5.

14. Tumilasci OR, Cersosimo MG, Belforte JE, Micheli FE, Benarroch EE, Pazo JH. Quantitative study of salivary secretion in Parkinson's disease. Mov Disord. 2006;21(5):660-7. https://doi. org/10.1002/mds.20784.

15. Proulx M, de Courval FP, Wiseman MA, Panisset M. Salivary production in Parkinson's disease. Mov Disord. 2005;20(2):204-7. https://doi.org/10.1002/mds.20189.

16. Nicaretta DH, de Rosso AL, Maliska C, Costa MM. Scintigraphic analysis of the parotid glands in patients with sialorrhea and Parkinson's disease. Parkinsonism Relat Disord. 2008;14(4):338-41. https://doi.org/10.1016/j.parkreldis.2007.07.008.

17. Cersosimo MG, Raina GB, Calandra CR, Pellene A, Gutierrez C, Micheli FE, Benarroch EE. Dry mouth: an overlooked autonomic symptom of Parkinson's disease. J Parkinson's Dis. 2011;1(2):169_ 73. https://doi.org/10.3233/jpd-2011-11021.

18. Leibner J, Ramjit A, Sedig L, Dai Y, Wu SS, Ct J, Okun MS, Rodriguez RL, Malaty IA, Fernandez HH. The impact of and the factors associated with drooling in Parkinson's disease. Parkinsonism Relat Disord. 2010;16(7):475-7. https://doi.org/10.1016/j. parkreldis.2009.12.003. 
19. Zadikoff C, Fox SH, Tang-Wai DF, Thomsen T, de Bie RM, Wadia P, Miyasaki J, Duff-Canning S, Lang AE, Marras C. A comparison of the mini mental state exam to the Montreal cognitive assessment in identifying cognitive deficits in Parkinson's disease. Mov Disord. 2008;23(2):297-9. https://doi.org/10.1002/mds.21837.

20. Zigmond AS, Snaith RP. The hospital anxiety and depression scale. Acta Psychiatrica Scand. 1983;67(6):361-70.

21. Martinez-Martin P, Benito-Leon J, Alonso F, Catalan MJ, Pondal M, Zamarbide I. Health-related quality of life evaluation by proxy in Parkinson's disease: approach using PDQ-8 and EuroQoL-5D. Mov Disord. 2004;19(3):312-8. https://doi.org/10.1002/ mds. 10656.

22. Chaudhuri KR, Pal S, DiMarco A, Whately-Smith C, Bridgman K, Mathew R, Pezzela FR, Forbes A, Hogl B, Trenkwalder C. The Parkinson's disease sleep scale: a new instrument for assessing sleep and nocturnal disability in Parkinson's disease. J Neurol Neurosurg Psychiatry. 2002;73(6):629-35. https://doi.org/10.1136/ jnnp.73.6.629.

23. Folstein MF, Robins LN, Helzer JE. The mini-mental state examination. Arch Gen Psychiatry. 1983;40(7):812.

24. Johns MW. A new method for measuring daytime sleepiness: the Epworth sleepiness scale. Sleep. 1991;14(6):540-5. https://doi. org/10.1093/sleep/14.6.540.

25. Hoehn MM, Yahr MD. Parkinsonism: onset, progression and mortality. Neurology. 1967;17(5):427-42. https://doi.org/10.1212/ wnl.17.5.427.

26. Marinus J, Visser M, Stiggelbout AM, Rabey JM, Martinez-Martin P, Bonuccelli U, Kraus PH, van Hilten JJ. A short scale for the assessment of motor impairments and disabilities in Parkinson's disease: the SPES/SCOPA. J Neurol Neurosurg Psychiatry. 2004;75(3):388-95. https://doi.org/10.1136/jnnp.2003.017509.

27. Martinez-Martin P, Schapira AH, Stocchi F, Sethi K, Odin P, MacPhee G, Brown RG, Naidu Y, Clayton L, Abe K, Tsuboi Y, MacMahon D, Barone P, Rabey M, Bonuccelli U, Forbes A, Breen K, Tluk S, Olanow CW, Thomas S, Rye D, Hand A, Williams AJ, Ondo W, Chaudhuri KR. Prevalence of nonmotor symptoms in Parkinson's disease in an international setting; study using nonmotor symptoms questionnaire in 545 patients. Mov Disord. 2007;22(11):1623-9. https://doi.org/10.1002/mds.21586.

28. Chaudhuri KR, Martinez-Martin P, Brown RG, Sethi K, Stocchi F, Odin P, Ondo W, Abe K, Macphee G, Macmahon D, Barone P, Rabey M, Forbes A, Breen K, Tluk S, Naidu Y, Olanow W, Williams AJ, Thomas S, Rye D, Tsuboi Y, Hand A, Schapira AH. The metric properties of a novel non-motor symptoms scale for Parkinson's disease: results from an international pilot study. Mov Disord. 2007;22(13):1901-11. https://doi.org/10.1002/mds.21596.

29. Erro R, Picillo M, Vitale C, Amboni M, Moccia M, Santangelo G, Pellecchia MT, Barone P. The non-motor side of the honeymoon period of Parkinson's disease and its relationship with quality of life: a 4-year longitudinal study. Eur J Neurol. 2016;23(11):16739. https://doi.org/10.1111/ene.13106.

30. Picillo M, Erro R, Amboni M, Longo K, Vitale C, Moccia M, Pierro A, Scannapieco S, Santangelo G, Spina E, Orefice G, Barone $\mathrm{P}$, Pellecchia MT. Gender differences in non-motor symptoms in early Parkinson's disease: a 2-years follow-up study on previously untreated patients. Parkinsonism Relat Disord. 2014;20(8):850-4. https://doi.org/10.1016/j.parkreldis.2014.04.023.

31. Fereshtehnejad SM, Zeighami Y, Dagher A, Postuma RB. Clinical criteria for subtyping Parkinson's disease: biomarkers and longitudinal progression. Brain. 2017;140(7):1959-76. https://doi. org/10.1093/brain/awx118.

32. Fereshtehnejad SM, Skogar O, Lokk J. Evolution of orofacial symptoms and disease progression in idiopathic parkinson's disease: longitudinal data from the jonkoping parkinson registry. Parkinson's Dis. 2017;2017:7802819. https://doi. org/10.1155/2017/7802819.
33. Ou R, Guo X, Wei Q, Cao B, Yang J, Song W, Chen K, Zhao B, Chen X, Shang H. Diurnal drooling in Chinese patients with Parkinson's disease. J Neurol Sci. 2015;353(1-2):74-8. https://doi. org/10.1016/j.jns.2015.04.007.

34. Chaudhuri KR, Prieto-Jurcynska C, Naidu Y, Mitra T, Frades-Payo B, Tluk S, Ruessmann A, Odin P, Macphee G, Stocchi F, Ondo W, Sethi K, Schapira AH, Martinez Castrillo JC, Martinez-Martin $\mathrm{P}$. The nondeclaration of nonmotor symptoms of Parkinson's disease to health care professionals: an international study using the nonmotor symptoms questionnaire. Mov Dis. 2010;25(6):704-9. https://doi.org/10.1002/mds.22868.

35. Nienstedt JC, Buhmann C, Bihler M, Niessen A, Plaetke R, Gerloff C, Pflug C. Drooling is no early sign of dysphagia in Parkinson's disease. Neurogastroenterol Motil. 2018;30(4):e13259. https://doi. org/10.1111/nmo.13259.

36. Reynolds H, Miller N, Walker R. Drooling in Parkinson's disease: evidence of a role for divided attention. Dysphagia. 2018;33(6):809-17. https://doi.org/10.1007/s00455-018-9906-7.

37. Evatt ML, Chaudhuri KR, Chou KL, Cubo E, Hinson V, Kompoliti K, Yang C, Poewe W, Rascol O, Sampaio C, Stebbins GT, Goetz CG. Dysautonomia rating scales in Parkinson's disease: sialorrhea, dysphagia, and constipation-critique and recommendations by movement disorders task force on rating scales for Parkinson's disease. Mov Disord. 2009;24(5):635-46. https://doi.org/10.1002/ mds. 22260 .

38. Martinez-Martin P, Rodriguez-Blazquez C, Abe K, Bhattacharyya KB, Bloem BR, Carod-Artal FJ, Prakash R, Esselink RA, Falup-Pecurariu C, Gallardo M, Mir P, Naidu Y, Nicoletti A, Sethi K, Tsuboi Y, van Hilten JJ, Visser M, Zappia M, Chaudhuri KR. International study on the psychometric attributes of the non-motor symptoms scale in Parkinson disease. Neurology. 2009;73(19):1584-91. https://doi.org/10.1212/WNL.0b013e3181 c0d416.

39. Wang G, Hong Z, Cheng Q, Xiao Q, Wang Y, Zhang J, Ma JF, Wang XJ, Zhou HY, Chen SD. Validation of the Chinese non-motor symptoms scale for Parkinson's disease: results from a Chinese pilot study. Clin Neurol Neurosurg. 2009;111(6):523-6. https://doi. org/10.1016/j.clineuro.2009.02.005.

40. Koh SB, Kim JW, Ma HI, Ahn TB, Cho JW, Lee PH, Chung SJ, Kim JS, Kwon DY, Baik JS. Validation of the korean-version of the nonmotor symptoms scale for Parkinson's disease. J Clin Neurol. 2012;8(4):276-83. https://doi.org/10.3988/jen.2012.8.4.276.

Publisher's Note Springer Nature remains neutral with regard to jurisdictional claims in published maps and institutional affiliations.

Daniel J. van Wamelen $\mathrm{MD}, \mathrm{PhD}$

Valentina Leta MD

Julia Johnson MSc

Claudia Lazcano Ocampo MD

Aleksandra M. Podlewska MSc

Katarina Rukavina MD

Alexandra Rizos MSc

Pablo Martinez-Martin MD, $\mathrm{PhD}$

K. Ray Chaudhuri MD, FRCP, DSc 